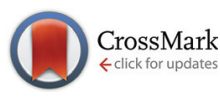

Cite this: Org. Biomol. Chem., 2015, 13,8556

\title{
Smaller, faster, better: modular synthesis of unsymmetrical ammonium salt-tagged NHC-gold(I) complexes and their application as recyclable catalysts in water $\dagger$
}

\author{
Katrin Belger and Norbert Krause*
}

Received 24th June 2015,

Accepted 8th July 2015

DOI: 10.1039/c5ob01286d

www.rsc.org/obc

\begin{abstract}
Facile access towards a small library of unsymmetrical ammonium salt-tagged $\mathrm{N}$-heterocyclic carbene gold(I) complexes is described, and their application as recyclable catalysts in cyclization reactions of acetylenic carboxylic acids and amides to lactones and lactams, respectively, in aqueous media is demonstrated. Catalyst $1 \mathrm{ab}$ was applied in the synthesis of 2-epi-clausemarine A (16).
\end{abstract}

\section{Introduction}

Sustainable chemistry is a frequently used term which indicates economic, ecological friendly and safe transformations. Accordingly, the development of new chemical reactions should combine waste prevention, use of nonhazardous solvents, and renewable raw materials. ${ }^{1}$ In organometallic chemistry, main objectives are reusable catalysts, easy separation of products, and prevention of side reactions. ${ }^{2}$ To achieve these goals, the use of water-soluble catalysts represents a desirable pathway. For this purpose, N-heterocyclic carbene (NHC) metal complexes were linked to water-soluble polymers ${ }^{3,4}$ or silicabased surfaces ${ }^{4}$ and carbohydrates. ${ }^{5}$ Moreover, they were functionalized with hydrophilic groups, such as carboxylates ${ }^{6,7}$ or sulfonates, ${ }^{7,8}$ resulting in improved water solubility and consequently an easier separation of the product and the catalyst, and also the opportunity for catalyst recycling. ${ }^{9,10}$

Since the first synthesis of a sulfonated NHC-metal complex by Herrmann et al., the number of reports about water-soluble NHC ligands has been increasing steadily. However, ammonium salt-tagged NHC ligands still play a minor role in transition metal catalysis, ${ }^{8}$ and only a limited number of publications deal with a direct synthesis of the ammonium function. ${ }^{11,12}$ More often, an amino group of the final NHC-metal complex is quaternized with a Brønsted acid. ${ }^{13-15}$ Recently, we reported the direct synthesis of ammonium salt-tagged IMesAuCl complexes and demonstrated their catalytic activity in cycloisomerization reactions of

Organic Chemistry, Dortmund University of Technology, Otto-Hahn-Str. 6, D-44227 Dortmund, Germany.E-mail: norbert.krause@tu-dortmund.de;

Fax: (+)492317553884

$\dagger$ Electronic supplementary information (ESI) available: Experimental details and NMR spectra. See DOI: 10.1039/c5ob01286d
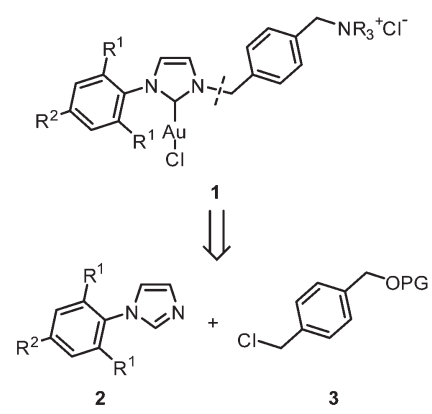

Fig. 1 Modular system for the synthesis of ammonium salt-tagged gold catalysts 1.

allenic and acetylenic alcohols in aqueous medium. ${ }^{11}$ Moreover, we could successfully demonstrate their high stability and recyclability in water.

Here, we report an even more facile access towards ammonium salt-functionalized NHC-gold complexes. A shortened synthetic pathway is achieved by the application of a modular system which provides access to a small library of gold catalysts $\mathbf{1}$. These ligands consist of an arylimidazole and a benzylic linker with an attached ammonium group (Fig. 1). The ammonium salt is introduced by aminoalkylation with trimethyl-, triethyl-, or tributylamine.

\section{Results and discussion}

The synthesis of the ammonium salt-tagged NHC-gold complexes 1 started with the formation of $N$-arylimidazoles $2 a$ and $2 \mathbf{b}$ (Scheme 1). These were obtained from commercially available 2,4,6-trimethylaniline and 2,6-diisopropylaniline, respect- 


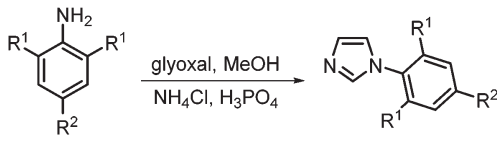

4a $R^{1}=R^{2}=M e$

4b $R^{1}=i \operatorname{Pr}, R^{2}=H$

2a $(46 \%)$

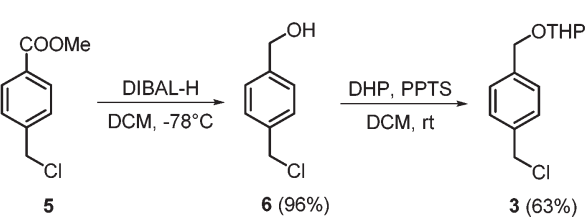

Scheme 1 Synthesis of building blocks 2 and 3 (DIBAL-H = diisobutylaluminum hydride; $\mathrm{DCM}=$ dichloromethane; $\mathrm{DHP}=3,4$-dihydro- $2 \mathrm{H}$ pyran; PPTS = pyridinium $p$-toluenesulfonate) .

ively, according to a literature procedure with similar yields to those reported. ${ }^{16}$ The second building block 3 was formed by reduction of methyl 4 -(chloromethyl)benzoate 5 with diisobutylaluminum hydride (DIBAL-H; 96\% yield) and tetrahydropyranyl-(THP)-protection of alcohol 6 (63\% yield).

The coupling of these building blocks was performed by heating $\mathbf{2 a}$ or $\mathbf{2 b}$ in acetonitrile in the presence of $\mathbf{3}$ to form the imidazolium salts $7 \mathbf{a}$ and $7 \mathbf{b}$ with $78 \%$ and $76 \%$ yield, respectively (Scheme 2). Here, the THP ether was cleaved during the acidic work-up. The alcohols 7 were chlorinated with thionyl chloride (90/96\% yield) and an aminoalkylation with trimethyl-, triethyl-, or tributylamine gave the desired carbene precursors 9 (66-86\% yield). These imidazolium salts were transformed into the corresponding gold(I) complexes in the presence of $\left(\mathrm{Me}_{2} \mathrm{~S}\right) \mathrm{AuCl}$ and potassium tert-butoxide. The NHC gold complexes 1 were obtained with $71-86 \%$ yield.

The catalytic activity of the new unsymmetrical ammonium salt-tagged gold catalysts $\mathbf{1}$ was investigated in cycloisomerization reactions of acetylenic carboxylic acids and amides. The gold-catalyzed lactonization of acetylenic carboxylic acids in water was previously examined by Cadierno et al. ${ }^{17}$ who used zwitterionic water-soluble gold complexes with sulfonate and

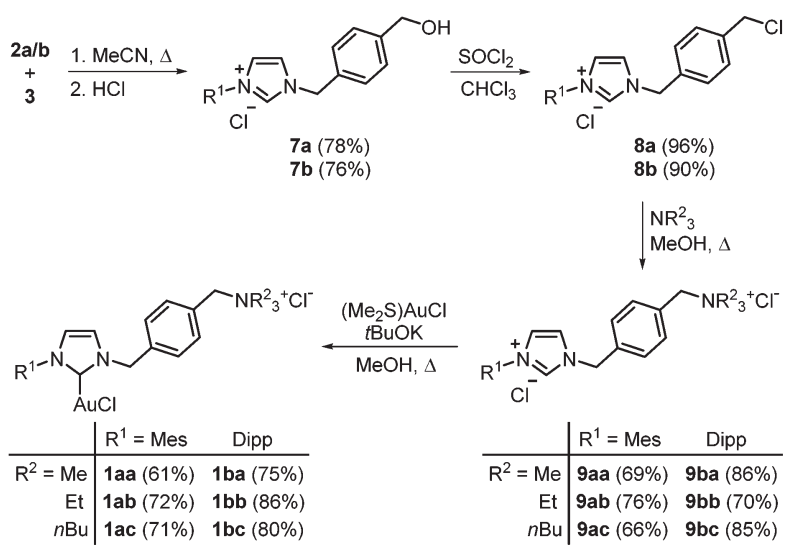

Scheme 2 Synthesis of unsymmetrical ammonium salt-tagged gold( $(1)$ complexes 1.
Table 1 Cycloisomerization of carboxylic acid 10a to lactone 11a in the presence of gold catalyst 1ab

\begin{tabular}{|c|c|c|c|c|}
\hline \multirow{2}{*}{$\begin{array}{l}\text { Medium } \\
\text { Cycle }\end{array}$} & \multicolumn{2}{|l|}{ Water } & \multicolumn{2}{|c|}{ Buffer solution $^{a}$} \\
\hline & Conv. $^{b}(\%)$ & Yield $^{c}(\%)$ & Conv. $^{b}(\%)$ & Yield $^{c}(\%)$ \\
\hline 1 & 99 & 78 & $>99$ & 89 \\
\hline 2 & 98 & 73 & $>99$ & 87 \\
\hline 3 & 87 & 72 & $>99$ & 88 \\
\hline 4 & 84 & 66 & 99 & 84 \\
\hline 5 & 79 & 63 & 97 & 81 \\
\hline
\end{tabular}

${ }^{a} 1.0 \mathrm{M}$ triethylammonium acetate solution $(\mathrm{pH}=7) .{ }^{b}$ Determined by ${ }^{1} \mathrm{H}$ NMR. ${ }^{c}$ Isolated yield.

pyridinium groups. Related studies were reported by Navarro Ranninger ${ }^{18}$ who applied platinum complexes and also investigated the hydrolysis of the lactone and its mechanism. Furthermore, copper and palladium complexes were also used in lactonization reactions of unsaturated carboxylic acids in aqueous medium. ${ }^{19,20}$ The corresponding cyclization of acetylenic amides to lactams was mainly performed in the presence of TBAF or bases in organic solvents. ${ }^{21,22}$ The only example of a metal-catalyzed cyclization was published by Nagasaka who used a lithium hexamethyldisilazide/AgOTf system. ${ }^{23}$ As far as we know, this reaction has not yet been carried out in water.

As a benchmark reaction, we first investigated the cyclization of 4-pentynoic acid (10a) to lactone 11a in the presence of gold catalyst 1ab at room temperature in water (Table 1). A recycling of catalyst $\mathbf{1} \mathbf{a b}$ after product extraction with diethyl ether showed decreasing conversions (99-79\%) and yields (78-63\%) over five cycles. As the measured $\mathrm{pH}$ value of pentynoic acid $\left(\mathrm{p} K_{\mathrm{a}}=4.21\right.$ (ref. 24)) in water is 2.44 , the gold complex slowly decomposed with the formation of a black precipitate in the acidic medium. The use of a triethylammonium acetate buffer solution with $\mathrm{pH}=7$ led to high conversions over five cycles and enhanced yields of $89-81 \%$. Notably, an activation of the gold catalyst with a silver salt is not necessary. At present, it is not clear whether complex $\mathbf{1}$ or a cationic gold species formed by dissociation of chloride is the catalytically active species, even though the rather high concentration of the strongly coordinating chloride anion (from the ammonium chloride side chain) in the reaction mixture certainly disfavors the latter. ${ }^{25}$

Next, we applied the full library of ammonium salt-tagged gold catalysts 1 to the cycloisomerization of different acetylenic carboxylic acids in aqueous buffer solution (Table 2). It turned out that the mesityl-substituted catalysts 1aa-ac gave better results than their 2,6-diisopropylphenyl-substituted counterparts $\mathbf{1 b a - 1 b c . ~ I n ~ p a r t i c u l a r , ~ c a t a l y s t ~ 1 a b ~ g a v e ~ h i g h ~ y i e l d s ~ o f ~}$ lactones $11(84-94 \%)$ in all cases. Even though the corresponding complex 1aa showed a similar reactivity, it gave lower yields $(69-86 \%)$ than $\mathbf{1 a b}$. These results were similar to $\mathbf{1 b b}$ 
Table 2 Cycloisomerization of carboxylic acids 10 to lactones 11 in the presence of gold catalysts 1 in aqueous buffer solution ${ }^{a}$

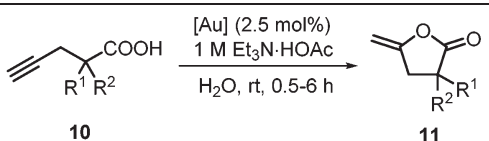

\begin{tabular}{|c|c|c|c|c|c|c|c|}
\hline \multicolumn{2}{|l|}{ Catalyst } & 1aa & $1 \mathrm{ab}$ & $1 \mathrm{ac}$ & $1 \mathrm{ba}$ & $1 \mathrm{bb}$ & $1 \mathrm{bc}$ \\
\hline Substrate & $\mathrm{R}^{1}, \mathrm{R}^{2}$ & \multicolumn{6}{|c|}{ Yield $^{b}(\%)$} \\
\hline $10 a$ & $\mathrm{H}, \mathrm{H}$ & 69 & 89 & 85 & 77 & 78 & 77 \\
\hline $10 \mathrm{~b}$ & $\mathrm{Me}, \mathrm{H}$ & 77 & 85 & 83 & 67 & 71 & 65 \\
\hline $10 c^{c}$ & iPr, H & 86 & 94 & 91 & 72 & 78 & 71 \\
\hline $\operatorname{10d}^{c}$ & $\mathrm{Ph}, \mathrm{H}$ & 72 & 84 & $77^{d}$ & 77 & 86 & $74^{d}$ \\
\hline $10 \mathrm{e}^{c, d}$ & $\mathrm{Ph}, \mathrm{Ph}$ & 81 & 84 & 72 & 71 & 76 & 69 \\
\hline
\end{tabular}

${ }^{a}$ Reaction times required for full conversion are given in the ESI. ${ }^{b}$ Isolated yield. ${ }^{c} 0.5 \mathrm{M}$ solution of the carboxylic acid in THF was used. ${ }^{d}$ At $50{ }^{\circ} \mathrm{C}$.

Table 3 Cycloisomerization of carboxylic acid 10a to lactone 11a in the presence of different amounts of gold catalyst 1ab in aqueous buffer solution

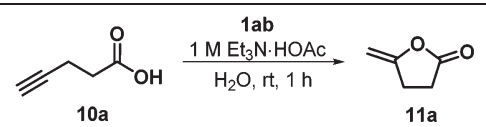

\begin{tabular}{llll}
\hline Entry & 1ab $(\mathrm{mol} \%)$ & Conversion $^{a}(\%)$ & Yield $^{a}(\%)$ \\
\hline 1 & 2.5 & $>99$ & 89 \\
2 & 1.0 & 97 & 83 \\
3 & 0.5 & 90 & 63 \\
4 & 0.1 & 57 & 37
\end{tabular}

${ }^{a}$ Determined by ${ }^{1} \mathrm{H}$ NMR (standard toluene).

(71-86\%). The addition of THF as the cosolvent to carboxylic acids 10c-e was necessary in order to dissolve the (otherwise insoluble) substrates. Moreover, for carboxylic acid 10e the temperature had to be raised to $50{ }^{\circ} \mathrm{C}$ to decrease the reaction time to $0.5-4 \mathrm{~h}$ (otherwise, full conversion was obtained only after $24 \mathrm{~h}$ at room temperature).

In order to render the transformation even more sustainable, we decreased the catalyst loading. As shown in Table 3, similar results were obtained for the cycloisomerization of carboxylic acid 10a to lactone 11a with $1 \mathrm{~mol} \%$ of $1 \mathrm{ab}$ instead of $2.5 \mathrm{~mol} \%$ (entry 2 vs. 1). Even lower catalyst loadings of 0.5 or $0.1 \mathrm{~mol} \%$ afforded incomplete conversion within $1 \mathrm{~h}$ (entries 3 and 4). However, increasing the reaction time to $3 \mathrm{~h}$ (with $0.5 \mathrm{~mol} \%$ of $1 \mathrm{ab} ; 79 \%$ yield) or $7 \mathrm{~h}$ (with $0.1 \mathrm{~mol} \% \mathrm{1ab} ; 74 \%$ yield) was sufficient to give a full conversion of 10a to 11a.

A possible side reaction to the cyclization is the gold-catalyzed hydration of the triple bond of the acetylenic acid in the aqueous reaction medium. This has been observed previously by other groups, ${ }^{17,18}$ but not (to this point) with the ammonium salt-tagged gold catalysts 1 . Cadierno et al. ${ }^{17}$ have

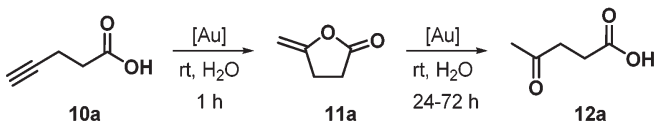

Scheme 3 Gold-catalyzed cycloisomerization of 4-pentynoic acid (10a) and hydrolytic ring-opening of lactone 11a.

Table 4 Cycloisomerization of amides 13 to lactams 14 in the presence of gold catalysts 1 in aqueous buffer solution ${ }^{a}$

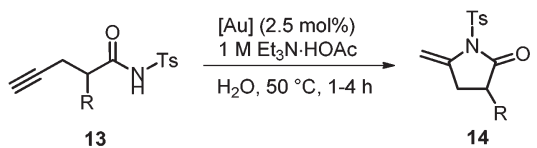

\begin{tabular}{|c|c|c|c|c|c|c|c|}
\hline \multicolumn{2}{|l|}{ Catalyst } & $1 \mathrm{aa}$ & $1 \mathrm{ab}$ & $1 \mathrm{ac}$ & $1 \mathrm{ba}$ & $1 \mathrm{bb}$ & $1 b c$ \\
\hline Substrate $^{b}$ & $\mathrm{R}$ & \multicolumn{6}{|c|}{ Yield $^{c}(\%)$} \\
\hline $13 \mathbf{a}$ & $\mathrm{H}$ & 95 & 92 & 89 & 86 & 90 & 92 \\
\hline $13 b$ & $\mathrm{Me}$ & 84 & 78 & 80 & 87 & 79 & 72 \\
\hline $13 \mathrm{c}$ & iPr & 85 & 80 & 82 & 78 & 84 & 75 \\
\hline 13d & $\mathrm{Ph}$ & 77 & 90 & 89 & 81 & 92 & 91 \\
\hline
\end{tabular}

${ }^{a}$ Reaction times required for full conversion are given in the ESI. ${ }^{b} 0.3$ $\mathrm{M}$ solution of the amide in THF was used. ${ }^{c}$ Isolated yield.

detected the formation of ketoacid 12a from 10a with gold complexes within $1 \mathrm{~h}$ at $\mathrm{rt}$, which led to moderate yields of lactone $11 \mathbf{a}(50 \%)$ in pure water (ratio of $\mathbf{1 1 a} / \mathbf{1 2 a}=3: 1$ ). With our catalyst 1ab, however, there were no traces of 12a or any other side product within this time (Table 1). Only after a prolonged reaction time of $24 \mathrm{~h}$ in pure water, we could isolate $21 \%$ of ketoacid 12a together with $50 \%$ of lactone 11a (Scheme 3). In the triethylammonium acetate buffer solution, similar yields were obtained after $24 \mathrm{~h}$ (12a: 18\%; 11a: 54\%). After 3 days in buffer solution, $43 \%$ of 12 a and $23 \%$ of 11a could be isolated, whereas in the absence of a gold catalyst, there was no formation of 12a. If we assume that the cyclization of 10a to 11a is irreversible, the ketoacid 12a is not formed by hydration of 10a but rather by a slow gold-catalyzed hydrolytic ring-opening of the lactone 11a. Accordingly, we could not observe any formation of acetophenone when phenylacetylene was heated to $60{ }^{\circ} \mathrm{C}$ for $24 \mathrm{~h}$ with gold complex 1ab in water. Under these conditions, only the more electron-rich 1-ethynyl-4-methoxybenzene gave $2 \%$ of the corresponding ketone.

In analogy to the acetylenic carboxylic acids 10, the corresponding tosylamides $13^{26}$ can be smoothly cyclized to the lactams 14 with the unsymmetrical ammonium salt-tagged gold catalysts $\mathbf{1}$ in aqueous medium (Table 4). As the measured $\mathrm{pH}$ value of amide 13a in water is 3.72 (calcd $\mathrm{p} K_{\mathrm{a}}=6.31$ ), we again used a buffer solution to avoid degradation of the catalyst. In general, all gold catalysts afforded high yields of lactams 13. Only complexes $\mathbf{1 a c} / \mathbf{1 b c}$ with tributylammonium groups needed extended reaction times of $2-4 \mathrm{~h}$ which has 


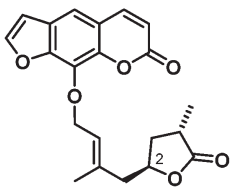

Clausemarine A (15)

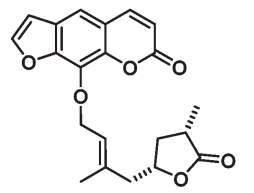

2-epi-Clausemarine A (16)
Fig. 2 Furanocoumarin clausemarine A (15) isolated from Clausena lansium, and its 2-epimer 16.

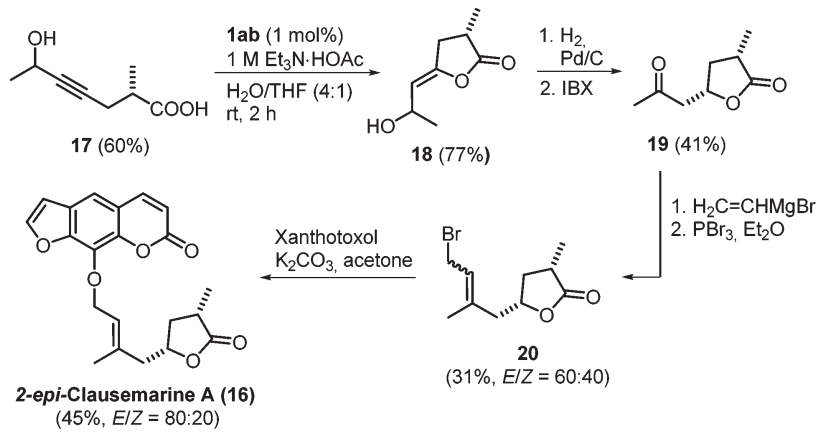

Scheme 4 Synthesis of 2-epi-clausemarine A (16).

also been observed for the formation of lactones 11. In contrast to lactone $11 \mathrm{a}$, treatment of lactam 13a with gold catalyst $\mathbf{1 a b}$ for $24 \mathrm{~h}$ at $50{ }^{\circ} \mathrm{C}$ did not afford any other product.

In order to apply the new gold catalysts 1 in target-oriented synthesis, we have chosen 2-epi-clausemarine A (16), an epimer of the furanocoumarin 15 which was isolated recently by $\mathrm{Wu}$ et al. $^{27}$ from Clausena lansium, a grape-like fruit in Southeast Asia (Fig. 2). This contains an $\alpha$-substituted lactone ring which can be formed by gold-catalyzed cyclization of a suitable acetylenic acid.

The substrate required for the gold-catalyzed step, the hydroxycarboxylic acid 17 (Scheme 4), was synthesized by Evans alkylation (see the ESI $\dagger$ for details). With $1 \mathrm{~mol} \%$ of our gold catalyst $\mathbf{1 a b}$ in aqueous triethylammonium acetate solution containing THF as the cosolvent, the desired lactone $\mathbf{1 8}$ was obtained with $77 \%$ yield. Hydrogenation of the double bond and subsequent oxidation of the hydroxy group with 2-iodoxybenzoic acid (IBX) gave the cis- $(S, S)$-diastereomer 19. Other hydrogenation catalysts such as $\mathrm{PtO}_{2}$ led to an opening of the lactone ring to the corresponding saturated hydroxycarboxylic acid. Treatment of 19 with vinylmagnesium bromide and $\mathrm{PBr}_{3}$ afforded the labile allyl bromide 20 as a mixture of $E$ / $Z$-isomers. Finally, conversion of $\mathbf{2 0}$ according to a known procedure $^{28}$ gave the target molecule 2-epi-clausemarine A (16).

\section{Conclusions}

We have developed new, rapid access to ammonium salttagged gold catalysts $\mathbf{1}$ with the possibility of further variation of their unsymmetrical structure. The modular approach allowed the synthesis of a small library of catalysts 1 with overall yields of $32-47 \%$ starting from building blocks 2 and 3 . Gold complexes 1 catalyze the cycloisomerization of acetylenic carboxylic acids and amides to the corresponding lactones and lactams in aqueous medium with good to excellent yields. An activation of the gold catalyst with a silver salt is not necessary. The acid-promoted degradation of the catalysts in pure water can be prevented by adjustment of the $\mathrm{pH}$ value to 7 . The recyclability of gold catalyst $\mathbf{1 a b}$ was demonstrated for the benchmark reaction of carboxylic acid 10a to lactone 11a. In contrast to previous gold catalysts operating in water, formation of ketoacids as a side product can be avoided with gold complexes 1. Moreover, we could successfully apply catalyst $\mathbf{1 a b}$ in the synthesis of 2-epi-clausemarine A (16). Further examples of sustainable gold catalysts will be reported in due course.

\section{Notes and references}

1 P. T. Anastas and J. C. Warner, Green Chemistry: Theory and Practice, Oxford University Press, Oxford, 1998.

2 (a) R. A. Sheldon, I. Arends and U. Hanefeld, Green Chemistry and Catalysis, Wiley-VCH, Weinheim, 2007; (b) K. Schröder, K. Matyjaszewski, K. J. T. Noonan and R. T. Mathers, Green Chem., 2014, 16, 1673-1686.

3 M. T. Zarka, M. Bortenschlager, K. Wurst, O. Nuyken and R. Weberskirch, Organometallics, 2004, 23, 4817-4820.

4 W. J. Sommer and M. Weck, Coord. Chem. Rev., 2007, 251, 860-873.

5 F. Tewes, A. Schlecker, K. Harms and F. J. Glorius, J. Organomet. Chem., 2007, 692, 4593-4602.

6 W. A. Herrmann, L. J. Goosen and M. J. Spiegler, J. Organomet. Chem., 1997, 547, 357-366.

7 L. R. Moore, S. M. Cooks, M. S. Anderson, H.-J. Schanz, S. T. Griffin, R. D. Rogers, M. C. Kirk and K. H. Shaughnessy, Organometallics, 2006, 25, 5151-5158.

8 L.-A. Schaper, S. J. Hock, W. A. Herrmann and F. E. Kühn, Angew. Chem., Int. Ed., 2013, 52, 270-289.

9 U. M. Lindström, Chem. Rev., 2002, 102, 2751-2772.

10 K. H. Shaughnessy, Chem. Rev., 2009, 109, 643-710.

11 K. Belger and N. Krause, Eur. J. Org. Chem., 2015, 220-225.

12 W. Wang, J. Wu, C. Xia and F. Li, Green Chem., 2011, 13, 3440-3445.

13 İ. Özdemir, B. Yiğit, B. Çetinkaya, D. Ülkü, M. N. Tahir and C. J. Arıcı, J. Organomet. Chem., 2001, 633, 27-32.

14 J. P. Jordan and R. H. Grubbs, Angew. Chem., Int. Ed., 2007, 46, 5152-5155.

15 S. L. Balof, S. J. P'Pool, N. J. Berger, E. J. Valente, A. M. Shiller and H.-J. Schanz, Dalton Trans., 2008, 57915799.

16 J. Liu, J. Chen, J. Zhao, Y. Zhao, L. Li and H. Zhang, Synthesis, 2003, 2661-2666.

17 (a) E. Thomás-Mendivil, P. Y. Toullec, J. Díez, S. Conejero, V. Michelet and V. Cadierno, Org. Lett., 2012, 14, 2520- 
2523; (b) E. Thomás-Mendivil, P. Y. Toullec, J. Borge, S. Conejero, V. Michelet and V. Cadierno, ACS Catal., 2013, 3, 3086-3098.

18 (a) J. Alemán, V. Del Solar, L. Cubo, A. G. Quiroga and C. Navarro Ranninger, Dalton Trans., 2010, 39, 10601-10607; (b) J. Aleman, V. Del Solar and C. Navarro-Ranninger, Chem. Commun., 2010, 46, 454456.

19 T. L. Mindt and R. J. Schibli, Org. Chem., 2007, 72, 1024710250.

20 (a) L. Zhou and H.-F. Jiang, Tetrahedron Lett., 2007, 48, 8449-8452; (b) K. Ogata, D. Sasano, T. Yokoi, K. Isozaki, H. Seike, H. Takaya and M. Nakamura, Chem. Lett., 2012, 41, 498-500; (c) J. García-Álvarez, J. Díez and C. Vidal, Green Chem., 2012, 14, 3190-3196.

21 (a) M. C. De La Fuente and D. Dominguez, J. Org. Chem., 2007, 72, 8804-8810; (b) P. A. Jacobi, S. C. Buddhu, D. Fry and S. Rajeswari, J. Org. Chem., 1997, 62, 2894-2906; (c) P. A. Jacobi and S. Rajeswari, Tetrahedron Lett., 1992, 33, 6231-6234.
22 (a) M. M. Cid, D. Dominguez, L. Castedo and E. M. Vazquez-Lopez, Tetrahedron, 1999, 55, 5599-5610; (b) J. Liu, Y. Zhang, G. Li, F. Roschangar, V. Farina, C. H. Senanayake and B. Z. Lu, Adv. Synth. Catal., 2010, 352, 2667-2671.

23 (a) Y. Koseki, S. Kusano and T. Nagasaka, Tetrahedron Lett., 1998, 39, 3517-3520; (b) Y. Koseki, S. Kusano, D. Ichi, K. Yoshida and T. Nagasaka, Tetrahedron, 2000, 56, 88558865.

24 J. S. Lomas, J. Phys. Org. Chem., 2012, 25, 620-627.

25 B. Ranieri, I. Escofet and A. M. Echavarren, Org. Biomol. Chem., 2015, 13, 7103-7118.

26 Synthesized from the corresponding carboxylic acid according to: K. S. Feldman, M. M. Bruendl, K. Schildknegt and A. C. Bohnstedt, J. Org. Chem., 1996, 61, 5440-5452.

27 D.-Y. Shen, Y.-Y. Chan, T.-L. Hwang, S.-H. Juang, S.-C. Huang, P.-C. Kuo, T. D. Thang, E.-J. Lee, A. G. Damu and T.-S. Wu, J. Nat. Prod., 2014, 77, 1215-1223.

28 E. C. Row, S. A. Brown, A. V. Stachulski and M. S. Lennard, Bioorg. Med. Chem., 2006, 14, 3865-3871. 